\title{
Comparison between intravenous boluses versus infusion of tranexamic acid (TXA) to reduce bleeding in paediatric cyanotic congenital heart disease (CHD) surgeries
}

Faisal Junejo

Aga Khan University

Mohammad Irfan Akhtar

Aga Khan University

Mohammad Hamid

Aga Khan University

Syed Shabbir Ahmed

Aga Khan University

Fauzia Minai

Aga Khan University, fauzia.minai@aku.edu

See next page for additional authors

Follow this and additional works at: https://ecommons.aku.edu/pakistan_fhs_mc_anaesth

Part of the Anesthesiology Commons

\section{Recommended Citation}

Junejo, F., Akhtar, M. I., Hamid, M., Ahmed, S. S., Minai, F., Amanullah, M. (2018). Comparison between intravenous boluses versus infusion of tranexamic acid (TXA) to reduce bleeding in paediatric cyanotic congenital heart disease (CHD) surgeries. Journal of the College of Physicians and Surgeons Pakistan, 28(3), 180-183.

Available at: https://ecommons.aku.edu/pakistan_fhs_mc_anaesth/141 
Authors

Faisal Junejo, Mohammad Irfan Akhtar, Mohammad Hamid, Syed Shabbir Ahmed, Fauzia Minai, and Muneer Amanullah 


\title{
Comparison between Intravenous Boluses versus Infusion of Tranexamic Acid (TXA) to Reduce Bleeding in Paediatric Cyanotic Congenital Heart Disease (CHD) Surgeries
}

\author{
Faisal Junejo, Mohammad Irfan Akhtar, Mohammad Hamid, Syed Shabbir Ahmed, \\ Fauzia Minai and Muneer Amanullah
}

\begin{abstract}
Objective: To compare the intravenous boluses and intravenous continuous infusion of tranexamic acid (TXA) to reduce postoperative bleeding in cyanotic congenital heart disease surgeries.

Study Design: Single-blinded randomised clinical trial.

Place and Duration of Study: Anaesthesia Department, The Aga Khan University Hospital, Karachi, from July 2016 to April 2017.

Methodology: Sixty patients of cyanotic congenital heart disease, undergoing either palliative or corrective surgery involving cardiopulmonary bypass (CPB), were recruited. These 60 patients were divided randomly into two groups. The infusion group received intravenous infusion of TXA at $5 \mathrm{mg} / \mathrm{kg} / \mathrm{hour}$ while the bolus group received three intravenous boluses of $10 \mathrm{mg} / \mathrm{kg}$ after induction, after going to bypass and after protamine reversal. Data was collected through predesigned proforma. There were two primary outcomes: postoperative bleeding in the first 24 hours, and chest closure time.

Results: Postoperative bleeding was $13.94(10.27-20.18) \mathrm{ml} / \mathrm{kg}$ in the first 24 hours in infusion group and 15.05 (9.04$23.50) \mathrm{ml} / \mathrm{kg}$ in the bolus group. Chest closure time was 38.5 (25-45) in infusion group and 30 (20-46.25) minutes in the bolus group. There was no statistically significant and clinical difference between both groups regarding postoperative bleeding in the first 24 hours and chest closure time.

Conclusion: These infusion and bolus groups had comparable postoperative bleeding and chest closure time.
\end{abstract}

Key Words: Tranexamic acid. Cyanotic congenital heart disease. Infusion. Bolus.

\section{INTRODUCTION}

Excessive bleeding in cardiac surgery increases morbidity and mortality. ${ }^{1,2}$ Children undergoing cardiac surgery are at high risk of bleeding due to the use of cardiopulmonary bypass circuit. 3,4 Bleeding exposes them to transfusion of blood products; hence, increases risk of transfusion complications. ${ }^{5}$ In cyanotic heart disease, there is an even higher risk of bleeding due to inherent platelet dysfunction and fibrinolysis. ${ }^{6}$

Implementation of a good blood conservation plan can reduce bleeding and improve outcome. ${ }^{7}$ TXA is the most common anti-fibrinolytic used in cardiac surgery. Systematic reviews suggest its use; and its safety is also compared with other anti-fibrinolytic drugs. 8,9

Cyanotic congenital heart disease including TOF, single ventricle physiology, refers to a subset of congenital heart disease $(\mathrm{CHD})$ that often present soon after birth

Department of Anaesthesia, The Aga Khan University Hospital, Karachi.

Correspondence: Dr. Faisal Junejo, Department of Anaesthesia, The Aga Khan University Hospital, Stadium Road, P.O. Box 3500, Karachi.

E-mail: fsl_junejo@hotmail.com

Received: July 28, 2017; Accepted: December 11, 2017. with systemic hypoxemia; and hypoxia is related to impaired pulmonary blood flow and mixing of pulmonary and systemic venous blood.10 Only a few researchers have used TXA as haemostatic agent in cyanotic congenital heart disease (CHD) surgeries in various doses and different regimens.

The aim of this study was to compare continuous infusion versus boluses of TXA in terms of reducing postoperative bleeding and chest closure time in cyanotic CHD surgeries.

\section{METHODOLOGY}

After ERC approval (4260-Ane-ERC-16) and consent from patients' parents, this randomised single-blinded clinical trial was conducted at cardiac operating rooms and $\mathrm{CICU}$ of The Aga Khan University Hospital, Karachi, from July 2016 to April 2017.

Inclusion criteria consisted of neonates to 16-year patient having first time on pump corrective or palliative cyanotic congenital heart surgery. Exclusion criteria included patients with renal dysfunction (serum creatinine $>1.5$ $\mathrm{mg} / \mathrm{dl}$ ), previous neurological event, congenital or acquired bleeding disorder (INR $>1.5$, history of easy bruisebility) and allergy to tranexamic acid $(1 \mathrm{ml}=50 \mathrm{mg}$ test dose to test allergy given before full dose). The 
sample size was based on postoperative mean blood loss for the first 24 hours of the patients in boluses group $20 \pm 13 \mathrm{ml} / \mathrm{kg} .{ }^{11} \mathrm{~A} 35 \%$ difference in the mean blood loss of (i.e. $13 \pm 5$ ) $\mathrm{ml} / \mathrm{kg}$ between the Tranexamic infusion and boluses groups was suggested to be considered significant. A sample size of 27 subjects in each group was considered sufficient to detect a $35 \%$ difference in blood loss with a power of 0.8 and type I error of 0.05 . It was assumed that the study dropout rate would be $10 \%$ and, therefore, a total of 60 patients (30 in each group) were recruited.

After enrolment, selected patients were randomly assigned into two groups using computer-generated randomisation (using software PASS, ver. 11.04 by randomisation algorithm). Group I (Infusion) patients got intravenous infusion of tranexamic acid at the rate of $5 \mathrm{mg} / \mathrm{kg} /$ hour. It was started after induction and continued throughout surgery and postoperatively until the bleeding minimised (chest tube output 0.5-1 $\mathrm{ml} / \mathrm{kg} / \mathrm{hr}$.). Group B (Bolus group) got three intravenous boluses of tranexamic acid at induction, on commencement of CPB, and after protamine reversal. Each bolus was of $10 \mathrm{mg} / \mathrm{kg}$.

Surgical and bypass technique was tailored according to the type of surgery. All patients were premedicated with $0.5 \mathrm{mg} / \mathrm{kg}$ midazolam syrup. Standard ASA monitoring was applied to all patients. Radial/femoral arterial lines and CVP (Right IJV or Femoral) lines were inserted in all patients.

Primary outcome measures were sternal closure time and postoperative bleeding. Chest closure was counted from completion of protamine administration till approximation of the sternum by tightening of sternal wires, and was documented in minutes. Postoperative bleeding was defined as bleeding occurring in $\mathrm{ml} / \mathrm{kg}$ after chest closure in the first 24 hours (at OR and $\mathrm{CICU}$ ). Pleur-Evac graduated suction was used to measure blood loss. Chest closure time in minutes and amount of postoperative bleeding was measured in $\mathrm{ml} / \mathrm{kg}$ for 24 hours by primary investigator and documented in the pre-designed data collection form. Other variables, according to data collection form, were also entered. Paediatric ICU team managed the patients postoperatively.

All statistical analyses were performed using Statistical Packages for Social Science version 19 (SPSS Inc., Chicago, IL). Normality of age, weight, height, time to chest closure, and postoperative bleeding was checked by Kolmogorov-Smirnov test, then student t-test and Mann-Whitney test were used to compare mean/median [25th - 75th percentile] difference between groups. Frequency and percentage was computed for gender. A value of $p \leq 0.05$ was considered as significant.

\section{RESULTS}

The mean age of the patients was 36.5 (13-63.75) months in group I (infusion) and 31 (17.5-75) months in group B (bolus). The mean body weight was 11 (8.7-14.1) $\mathrm{Kg}$ in group I and 12 (8.4-16.6) $\mathrm{Kg}$ in group $\mathrm{B}$ as shown in Table I. Patients underwent various types of surgeries, largely correction of Tetralogy of Fallot. The median bypass time was 100 [80-126.25] minutes in group I and 95 [75-131.75] minutes in group $B$. The median crossclamp was 75 [58-92.5] minutes in group I and 65 [53.75-90] minutes in group $B$.

Chest closure time in group I was 38.5 (25-45) minutes while in group B it was $30(20-46.25)$ minutes. Postoperative bleeding in first 24 hours in group I was $13.94(10.27-20.18) \mathrm{ml} / \mathrm{kg}$ and in group $B$ it was 15.05 $(9.04-23.50) \mathrm{ml} / \mathrm{Kg}$. There was no significant statistical difference regarding postoperative bleeding at any time in the first 24 hours, and chest closure time between the two groups (Table II).

The frequency of blood products usage was also analysed. Packed RBCs were required in $12(40 \%)$ patients of group I; whereas, it was $13(43.3 \%)$ in group B patients. Platelets were required in $15(50 \%)$ patients of group I and in $15(50 \%)$ patients of group B. Fresh frozen plasmas (FFPs) were required in $4(13.3 \%)$ patients of group I; whereas, $3(10 \%)$ patients of group B were transfused with FFPs. Cryoprecipitate were required in $13(43.3 \%)$ patients of group I; whereas, in 14 $(46.7 \%)$ patients of group B. Whole blood was used in 2 $(6.7 \%)$ and $6(20 \%)$ patients in group I and group B, respectively (Table III).

Table I: Demographic and surgical statistics of patients.

\begin{tabular}{|c|c|c|c|}
\hline Variables & $\begin{array}{l}\text { Group I } \\
(n=30)\end{array}$ & $\begin{array}{c}\text { Group B } \\
(\mathrm{n}=30)\end{array}$ & P-value \\
\hline Age (Months) ${ }^{\star}$ & $36.5[13-63.75]$ & $31[17.5-75]$ & 0.842 \\
\hline Height $(\mathrm{cm})^{*}$ & $91[81.25-101]$ & $90[77.13-109.75]$ & 0.935 \\
\hline Weight $(\mathrm{kg})^{*}$ & $11[8.7-14.1]$ & $12[8.4-16.6]$ & 0.912 \\
\hline BMI $(\mathrm{kg} / \mathrm{m} 2)^{*}$ & $13.9[12.5-15.2]$ & $14.1[12.2-14.8]$ & 0.941 \\
\hline \multicolumn{4}{|l|}{ Gender** } \\
\hline Male & $16(53.3 \%)$ & $15(50 \%)$ & 0.796 \\
\hline Female & $14(46.7 \%)$ & $15(50 \%)$ & \\
\hline \multicolumn{4}{|l|}{ Procedure $^{* *}$} \\
\hline TOF repair & $24(80 \%)$ & $22(73.3 \%)$ & \\
\hline Glenn Shunt & $3(10 \%)$ & $3(10 \%)$ & \\
\hline Senning procedure & $2(6.6 \%)$ & 0 & \\
\hline Correction of TAPVR & 0 & $2(6.6 \%)$ & \\
\hline Correction of Cor-triatriatum & $1(3.3 \%)$ & 0 & 0.934 \\
\hline Arterial switch & 0 & $1(3.3 \%)$ & \\
\hline Rastelli & 0 & $1(3.3 \%)$ & \\
\hline VSD Closure + RV myomectomy & 0 & $1(3.3 \%)$ & \\
\hline Bypass time (Min) * & $100[80-126.25]$ & $95[75-131.75]$ & 0.871 \\
\hline Cross Clamp Time (Min) * & $75[58-92.5]$ & $65[53.75-90]$ & 0.291 \\
\hline
\end{tabular}

Data are presented as *median [25th -75th Percentile], tmean \pm SD and $\ddagger n$ (\%) Statistical Test: *Mann-Whitney U-test, ${ }^{* *}$ Chi-square test. 
Table II: Comparison of postoperative bleeding $(\mathrm{ml} / \mathrm{kg})$ and chest closure time (minutes) between groups.

\begin{tabular}{|c|c|c|c|c|c|}
\hline \multirow[t]{2}{*}{ Variables } & \multicolumn{2}{|r|}{$\begin{array}{c}\text { Group I } \\
n=30\end{array}$} & \multicolumn{2}{|r|}{$\begin{array}{c}\text { Group B } \\
n=30\end{array}$} & \multirow[t]{2}{*}{ P-value } \\
\hline & $\mathrm{n}$ & Median [25th-75th Percentile] & $\mathrm{N}$ & Median [25th-75th Percentile] & \\
\hline At 6 hours & 30 & $7.40[4.32-11.42]$ & 30 & $7.62[4.31-11.63]$ & 0.97 \\
\hline 6-12 hours & 30 & $3.07[2.03-4.38]$ & 30 & $2.20[1.08-3.78]$ & 0.24 \\
\hline $12-18$ hours & 30 & $2.19[1.48-2.51]$ & 30 & $2.89[1.50-4.84]$ & 0.13 \\
\hline 18-24 hours & 30 & $1.25[0.18-2.23]$ & 30 & $1.15[0.0-2.37]$ & 0.88 \\
\hline Total postoperative bleeding in 1st 24 hours & 30 & $13.94[10.27-20.18]$ & 30 & $15.05[9.04-23.50]$ & 0.679 \\
\hline Chest closure time & 30 & $38.5[25-45]$ & 30 & $30[20-46.25]$ & 0.152 \\
\hline
\end{tabular}

Data are presented as median [25th -75th Percentile]. Statistical test: Mann-Whitney U-test.

Table III: Blood products and its component used.

\begin{tabular}{lccc}
\hline Use of blood products & $\begin{array}{c}\text { Group I } \\
(\mathrm{n}=30)\end{array}$ & $\begin{array}{c}\text { Group B } \\
(\mathrm{n}=30)\end{array}$ & P-value \\
\hline Priming of CPB circuit with blood product: & & \\
PRBCs & $18(60 \%)$ & $15(50 \%)$ & 0.436 \\
FFPs & $8(26.7 \%)$ & $4(13.3 \%)$ & 0.197 \\
\hline Blood product usage (In OR and CICU first $24 \mathrm{hrs}):$ & & \\
PRBCs & $12(40 \%)$ & $13(43.3 \%)$ & 0.793 \\
Platelets & $15(50 \%)$ & $15(50 \%)$ & 0.999 \\
FFPs & $4(13.3 \%)$ & $3(10 \%)$ & 0.688 \\
Cryoprecipitate & $13(43.3 \%)$ & $14(46.7 \%)$ & 0.795 \\
Whole Blood & $2(6.7 \%)$ & $6(20 \%)$ & 0.254 \\
\hline
\end{tabular}

Data are presented $n(\%)$, mean $\pm S D$ (min-max); Statistical Test: Chi-square test.

\section{DISCUSSION}

This study found no statistical difference between two regimens of TXA with respect to postoperative bleeding in the first 24 hours and chest closure time. Furthermore, any adverse major clinical outcome as renal, neurological or thromboembolic event were not found. In this study, there was a very much homogenous population of patients in terms of age, height, weight, distribution of gender and type of surgery. All the surgeries were done by one surgeon.

In another study, Couturier and colleagues sought to assess the effectiveness of continuous and discontinuous TXA by fibrinolytic parameters in on-pump paediatric cardiac surgery. They also concluded that continuous and discontinuous both inhibit fibrinolysis effectively. ${ }^{12}$

A study by Chauhan and colleagues used five different regimens among which bolus group had decreased blood loss among all groups, but maximum reduction was in bolus group of $10 \mathrm{mg} / \mathrm{kg}$ after induction, on CPB and after Protamine. In this study, there was no statistical difference in post-op bleeding in both groups. However, there is less bleeding and less use of blood and blood products in comparison to study of Chauhan and colleagues. ${ }^{11}$

A study conducted by Faraoni and colleagues on the effect of two doses of tranexamic acid on fibrinolysis evaluated by thromboelastography stated no difference between two different doses of TXA and placebo regarding fibrinolysis. ${ }^{13}$ In another study in adults, Sigaut and colleagues observed high and low doses of tranexamic acid in terms of blood transfusion and found no difference but higher dose was more effective in terms of post-op bleeding and reopening. 14

In a multicentre contemporary analysis of anti-fibrinolytic medication in paediatric cardiac surgery, Pasquali and colleagues found that TXA was associated with improved outcomes in comparison to aprotinin, like decrease in hospital mortality, bleeding requiring surgical intervention, ICU length of stay and dialysis. In redo-sternotomies, there were no differences detected between TXA and aprotinin. ${ }^{15}$

In a RCT, Reid and colleagues found that TXA effectively reduces blood loss in children undergoing repeat cardiac surgeries, although the dose used was high but still they haven't found any adverse event or complication of TXA. Total volume transfusion requirements and total unit exposure to banked blood components were also less in the tranexamic acid group. ${ }^{16}$

Additionally, a study by Schindler and colleagues collected data retrospectively and compared TXA as an alternative to aprotinin in paediatric cardiac surgery and suggested that TXA represent adequate alternation to aprotinin in congenital cardiac surgery. ${ }^{17}$

Chauhan and colleagues studied effectiveness of TXA in corrective surgeries of cyanotic CHD and proved that the TXA is highly effective in reducing postoperative bleeding and use of blood and blood products. ${ }^{18}$ Furthermore, a retrospective study of $\mathrm{CHD}$ patients undergoing cardiac surgery, Giordano and colleagues showed that TXA significantly decreases postoperative bleeding and reduces intra-op and post-op RBCs transfusion. ${ }^{19}$

A study conducted by Martin and colleagues compared TXA with e-ACA (epsilon-aminocaproic acid) and found that there was no difference between both drugs in terms of blood loss, revision of surgery due to bleeding, and blood transfusion. They also found that there was no difference in major clinical outcomes as renal, neurological, cardiovascular complications, and in hospital mortality. 20 In a retrospective study Hasegawa and colleagues evaluated the effectiveness of intraoperative TXA in blood-less cardiac surgery in children and found that intraoperative TXA was effective for both blood conservation and post-op clinical outcomes. ${ }^{21}$ In another study, Patel and colleagues studied to determine the effectiveness of Topical TXA in 
paediatric cardiac surgery. They concluded that the combination of low dose systemic TXA and topical TXA intrapericadially before chest closure was the best. ${ }^{22}$ In a clinical review, William and colleagues observed that practice of TXA as antifibrinolytic in intra-op and peri-op settings has strong pharmacological and clinical grounds. They found that TXA can be used effectively in adult cardiac surgery, paediatric cardiac and non-cardiac surgery, orthopaedic surgery, neurosurgery, hepatic surgery, and gynaecology and obstetrics surgeries. ${ }^{23}$

The limitation of this study was attributed to its small sample size, majority of the cases were correction of TOF, and it was also a single-blinded study. Therefore in future, a large sample size study needs to be conducted to validate these results. The lack of statistically significant difference among the groups may be evaluated in a further high sample size and adequately powered study with more standardised anaesthetic, surgical, and bypass techniques.

\section{CONCLUSION}

There was no statistical and clinical difference between infusion and bolus group with respect to postoperative bleeding and chest closure time. However, postoperative bleeding was little less in volume in infusion group, but paradoxically chest closure time was little less in bolus group.

\section{REFERENCES}

1. Ranucci M, Baryshnikova E, Castelvecchio S, Pelissero G, Surgical, Group COR. Major bleeding, transfusions, and anemia: the deadly triad of cardiac surgery. Ann Thorac Surg 2013; 96:478-85.

2. Petäjä J, Lundström U, Leijala M, Peltola K, Siimes MA. Bleeding and use of blood products after heart operations in infants. J Thorac Cardiovasc Surg 1995; 109:524-9.

3. Bronicki RA, Hall M. Cardiopulmonary bypass-induced inflammatory response: pathophysiology and treatment. Pediatr Crit Care Med 2016; 17(8_suppl):S272-S8.

4. Kraft F, Schmidt C, Van Aken H, Zarbock A. Inflammatory response and extracorporeal circulation. Best Pract Res Clin Anaesthesio 2015; 29:113-23.

5. Spiess BD. Blood transfusion and infection after cardiac surgery. Ann Thorac Surg 2013; 95:1855-8.

6. Tempe DK, Virmani S. Coagulation abnormalities in patients with cyanotic congenital heart disease. J Cardiothorac Vasc Anesth 2002; 16:752-65.

7. LaPar DJ, Crosby IK, Ailawadi G, Ad N, Choi E, Spiess BD, et al. Blood product conservation is associated with improved outcomes and reduced costs after cardiac surgery. $J$ Thorac Cardiovasc Surg 2013; 145:796-804.

8. Ker K, Edwards P, Perel P, Shakur H, Roberts I. Effect of tranexamic acid on surgical bleeding: systematic review and cumulative meta-analysis. BMJ 2012; 344:e3054.
9. Lin CY, Shuhaiber JH, Loyola H, Liu H, del Nido P, DiNardo JA, et al. The safety and efficacy of antifibrinolytic therapy in neonatal cardiac surgery. PloS One 2015; 10:e0126514.

10. Opotowsky AR, Moko LE, Ginns J, Rosenbaum M, Greutmann M, Aboulhosn $\mathrm{J}$, et al. Pheochromocytoma and paraganglioma in cyanotic congenital heart disease. J Clin Endocrinol Metab 2015; 100:1325-34

11. Chauhan S, Bisoi A, Kumar N, Mittal D, Kale S, Kiran U, et al. Dose comparison of tranexamic acid in pediatric cardiac surgery. Asian Cardiovasc Thorac Ann 2004; 12:121-4.

12. Couturier R, Rubatti M, Credico C, Louvain-Quintard V, Anerkian V, Doubine $\mathrm{S}$, et al. Continuous or discontinuous tranexamic acid effectively inhibits fibrinolysis in children undergoing cardiac surgery with cardiopulmonary bypass. Blood Coagul Fibrinolysis 2014; 25:259-65.

13. Faraoni D, Cacheux C, Van Aelbrouck C, Ickx BE, Barvais L, Levy $\mathrm{JH}$. Effect of two doses of tranexamic acid on fibrinolysis evaluated by thromboelastography during cardiac surgery: a randomised, controlled study. Eur J Anaesthesiol 2014; 31: 491-8.

14. Sigaut S, Tremey B, Ouattara A, Couturier R, Taberlet C, Grassin-Delyle $S$, et al. Comparison of two doses of tranexamic acid in adults undergoing cardiac surgery with cardiopulmonary bypass. J Am Soc Anesthesiol. 2014; 120: 590-600.

15. Pasquali SK, Li JS, He X, Jacobs ML, O'Brien SM, Hall M, et al. Comparative analysis of antifibrinolytic medications in pediatric heart surgery. J Thorac Cardiovasc Surg 2012; 143: 550-7.

16. Reid RW, Zimmerman AA, Laussen PC, Mayer JE, Gorlin JB, Burrows FA. The efficacy of tranexamic acid versus placebo in decreasing blood loss in pediatric patients undergoing repeat cardiac surgery. Anesth Analg 1997; 84:990-6.

17. Schindler E, Photiadis J, Sinzobahamvya N, Döres A, Asfour B, Hraska V. Tranexamic acid: an alternative to aprotinin as antifibrinolytic therapy in pediatric congenital heart surgery. Eur J Cardiothorac Surg 2011; 39:495-9.

18. Chauhan S, Bisoi A, Modi R, Gharde P, Rajesh M. Tranexamic acid in paediatric cardiac surgery. Indian J Med Res 2003; 118:86.

19. Giordano R, Palma G, Poli V, Palumbo S, Russolillo V, Cioffi S, et al. Tranexamic acid therapy in pediatric cardiac surgery: a single-center study. Ann Thorac Surg 2012; 94:1302-6.

20. Martin K, Breuer T, Gertler R, Hapfelmeier A, Schreiber C, Lange $\mathrm{R}$, et al. Tranexamic acid versus $\varepsilon$-aminocaproic acid: efficacy and safety in paediatric cardiac surgery. Eur $J$ Cardiothorac Surg 2011; 39:892-7.

21. Hasegawa T, Oshima $Y$, Maruo A, Matsuhisa $H$, Tanaka A, Noda $\mathrm{R}$, et al. Intraoperative tranexamic acid in pediatric bloodless cardiac surgery. Asian Cardiovasc Thorac Ann 2014; 22:1039-45

22. Patel J, Prajapati M, Patel H, Gandhi H, Deodhar S, Pandya H. Topical and low-dose intravenous tranexamic acid in cyanotic cardiac surgery. Asian Cardiovasc Thorac Ann 2017; 25:118-22.

23. Ng WCK, Jerath A, Wasowicz M. Tranexamic acid: a clinical review. Anaesthesiol Intensive Ther 2015; 47:339-50. 